\title{
Article
}

\section{Open Source Digitally Replicable Lab-Grade Scales}

\author{
Benjamin R. Hubbard ${ }^{1}$ and Joshua M. Pearce ${ }^{2,3,4, *}$
}

1 Department of Mechanical Engineering-Engineering Mechanics, Michigan Technological University, Houghton, MI 49931, USA; brhubbar@mtu.edu

2 Department of Electrical \& Computer Engineering, Michigan Technological University, Houghton, MI 49931, USA

3 Department of Material Science \& Engineering, Michigan Technological University, Houghton, MI 49931, USA

4 Department of Electronics and Nanoengineering, School of Electrical Engineering, Aalto University, Espoo, FI-00076, Finland

* Correspondence: pearce@mtu.edu; Tel.: +01-906-487-1466

\begin{abstract}
:
This study provides designs for a low-cost, easily replicable open source lab-grade digital scale that can be used as a precision balance. The design is such that it can be manufactured for use in most labs throughout the world with open source RepRap-class material extrusion-based 3-D printers for the mechanical components and readily available open source electronics including the Arduino Nano. Several versions of the design were fabricated and tested for precision and accuracy for a range of load cells. The results showed the open source scale was found to be repeatable within $0.1 \mathrm{~g}$ with multiple load cells, with even better precision $(0.01 \mathrm{~g})$ depending on load cell range and style. The scale tracks linearly with proprietary lab-grade scales, meeting the performance specified in the load cell data sheets, indicating that it is accurate across the range of the load cell installed. The smallest loadcell tested(100g) offers precision on the order of a commercial digital mass balance. The scale can be produced at significant cost savings compared to scales of comparable range and precision when serial capability is present. The cost savings increase significantly as the range of the scale increases and are particularly well-suited for resource-constrained medical and scientific facilities.
\end{abstract}

Keywords: 3-D printing; additive manufacturing; distributed manufacturing; laboratory equipment; open hardware; open source; open source hardware; scale; balance; mass

\section{Introduction}

The incredible success of free and open source development of software [1,2] is being rapidly adopted by the hardware community $[3,4]$ as it enables scientific equipment designers to rapidly build upon one another's work [5-7]. This has resulted in a democratization of design building on open source designs [8-10] often with open source tools that enable a true digital distributed manufacturing [11-14]. The most robust examples, is the self-replicating rapid prototype (RepRap) fused filament fabrication (FFF)-based 3-D printer [15-17] that has brought the cost of both rapid prototyping and additive manufacturing low enough to be used by the masses [18-21]. FFF-based 3D printers derived from RepRaps now have 3-D printed parts with sufficient mechanical strength [22] to be used for final functional parts even if printed on machines that only cost a few hundred dollars. This has resulted in an explosion of open source digitally fabricated instruments and a repository of designs housed at the NIH $[5,6,23,24]$. There are many examples of progressively more sophisticated open source 3-D printed parts being used to build chemical mixing systems [22-25], mechanical components for optics setups [26-31] and microscopes [32-34], instruments to test water quality testing [35-38], various types of syringe pumps [39-43] that are combined with other components to 
make complete systems for making microfluidics and metafluidics [44-47]. Although the most important features of open source 3-D printable instruments is the ease with which scientists can customize a tool, in general, they are also much less expensive than equivalent (and often technically inferior) commercial proprietary systems $[6,23,24,48-50]$ and provide a high return on investment [51,52]. This advantage expands as the device is made with a higher percentage of digitally replicable components [53]. To continue this tradition of standing on the shoulders of open hardware giants [54], this paper describes the design of an open source largely 3-D printed digital scale. A digital scale is a scientific instrument that provides fast measurements of mass generally with an accuracy range of 0.1 gram to 0.01 gram and have easy-to-read automatic liquid crystal displays. (Accuracy refers to closeness of the measurements to a specific value of the mass. On the other hand, precision refers to the closeness of the measurements to one another.) Digital scales are used in a wide range of scientific applications from chemical research, genomics, drug discovery, and proteomics. Scales are classified by precision; where a precision balance has a measurement resolution of 0.001 gram, an analytical balance has one of 0.0001 gram and a micro balance has one of 0.0000001 gram. On the high-end of scales an open source quartz crystal microbalance (OpenQCM) [55] uses an open source Arduino Nano and is already well established in the scientific literature [56-60].

Thus, this study provides the designs for a low-cost, easily replicable open source lab-grade digital scale that can be used as a precision balance depending on configuration. The design is such that it can be manufactured for use in most labs throughout the world with open source RepRapclass material extrusion-based 3-D printers for the mechanical components and readily available open source electronics including the Arduino Nano. In addition, a validation procedure for quantifying the accuracy and precision is provided. Several versions of the design were fabricated and tested for a range of load cells, and the results are discussed in the context of resource-constrained medical and scientific facilities.

\section{Materials and Methods}

\subsection{Design}

This series of open source scales, based on load cells, was designed to be easily manufacturable, require minimal components, and offer the functionality necessary for a basic digital scale, a precision balance and an analytical balance. Component location is accomplished entirely by features on the 3D printed components including bosses and snap-fit joints, meaning that the only fasteners required are those that hold the loadcell in place. The assembly was designed to fully enclose all electronics, limiting airflow, which has been observed to affect the output of the loadcell amplifier.

At the time of writing, the scale is designed to accommodate two sizes of single-point parallel beam loadcells - TAL220 and TAL221 - but is set up to enable fast adaptation to other models. These were selected first due to their low cost, wide selection of weight ranges, and insensitivity to moment loading on the bed, which aids in measurement repeatability [61]. The base and bed were designed to be easily modified to accommodate other loadcell styles as required.

The open source scale systems were designed for use in two settings: (1) as an independent digital scale with a displayed output which can be tared and calibrated without use of a computer, and (2) as a serially connected logging instrument for a laboratory setting and data logging. The serial capability also allows this scale to be constructed without an LCD, offering a significant cost reduction for uses that do not require a display, such as automated weighing or cases where a computer will always be used as the power supply.

In order to accomplish independent functionality, components were specified to ensure that the entire scale can be powered by a 5V USB power supply, either from a computer USB port or cell phone charging block, both of which are commonly available at low cost. The components' power requirements are small enough that the low-current digital pins on an Arduino can power them, allowing independent control of power to each component, which is leveraged in the implementation of power-saving features [62-64]. The scale's tare and calibration functions are controlled with a single push-button - pressed for tare, and held for several seconds to calibrate. 
As a logging scale, the microcontroller is configured to interface serially with a computer. The API for serial communication is built to comply with SMA SCP-0499 Level \#2 for limited-feature digital scale serial communication protocol. This includes capability to serially query the scale output, command tare, calibration, and provide basic scale information [65]. The API allows for continuous tracking of the scale readout for data-logging, which is useful for automated data-collection in cases such as long-term mass-tracking and discrete automated processes such as melt flow indexing (MFI).

\subsection{Bill of Materials}

The bill of materials (BOM) is shown in Table 1.

Table 1. Visual bill of materials separated by mechanical and electrical components.

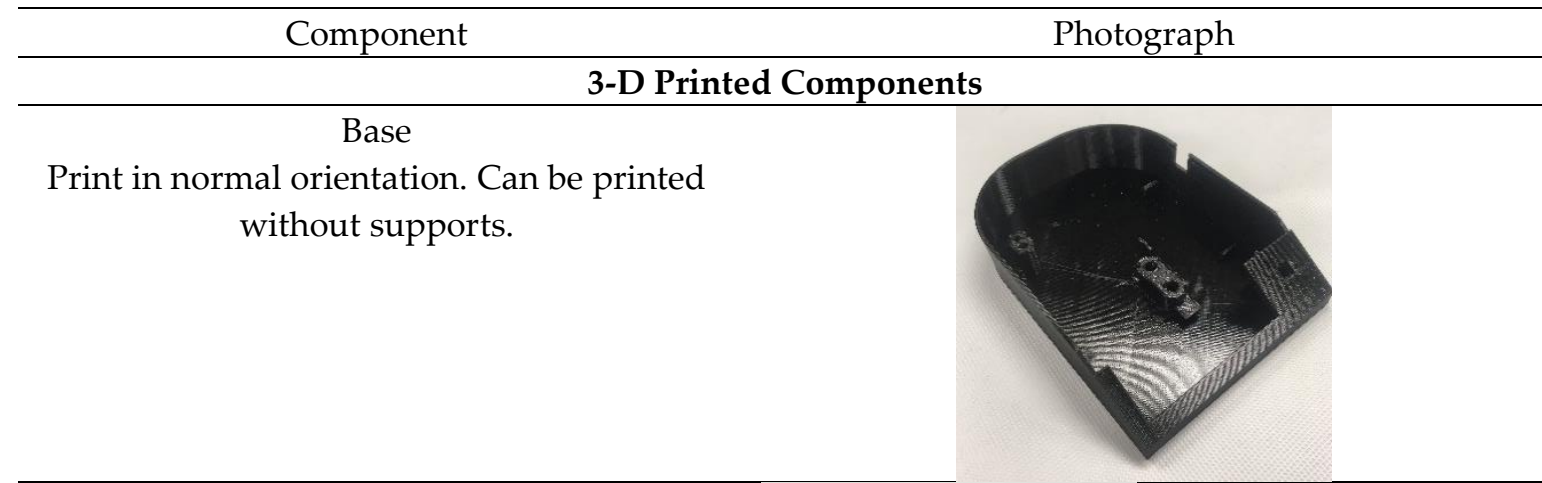

Cover

Print in either orientation. Can be printed without support, but this sacrifices top finish.

Bed

Print in either orientation. Can be printed without support, but this sacrifices top finish.

Cover (Optional)

Print upside-down without supports. This is used to reduce air currents for higher accuracy and precision. 


\section{Electronic Components}

Arduino Microcontroller (Nano) $\$ 20.70$ [66]

(Derivative available with cable for $\$ 5.72$

[67])

USB-A to mini-B USB (or micro, or USB-B, depending on the specific Arduino in use) $\$ 5.26$ [68]

5V USB Power Block (Optional) $\$ 4.00$ [69]

Push Button (Normally Open, Momentary) $\$ 2.50$ for 20 pack [71]

HX711 Loadcell Amplifier

$\$ 8.50$ with TAL220 [70]

Jumper Wires




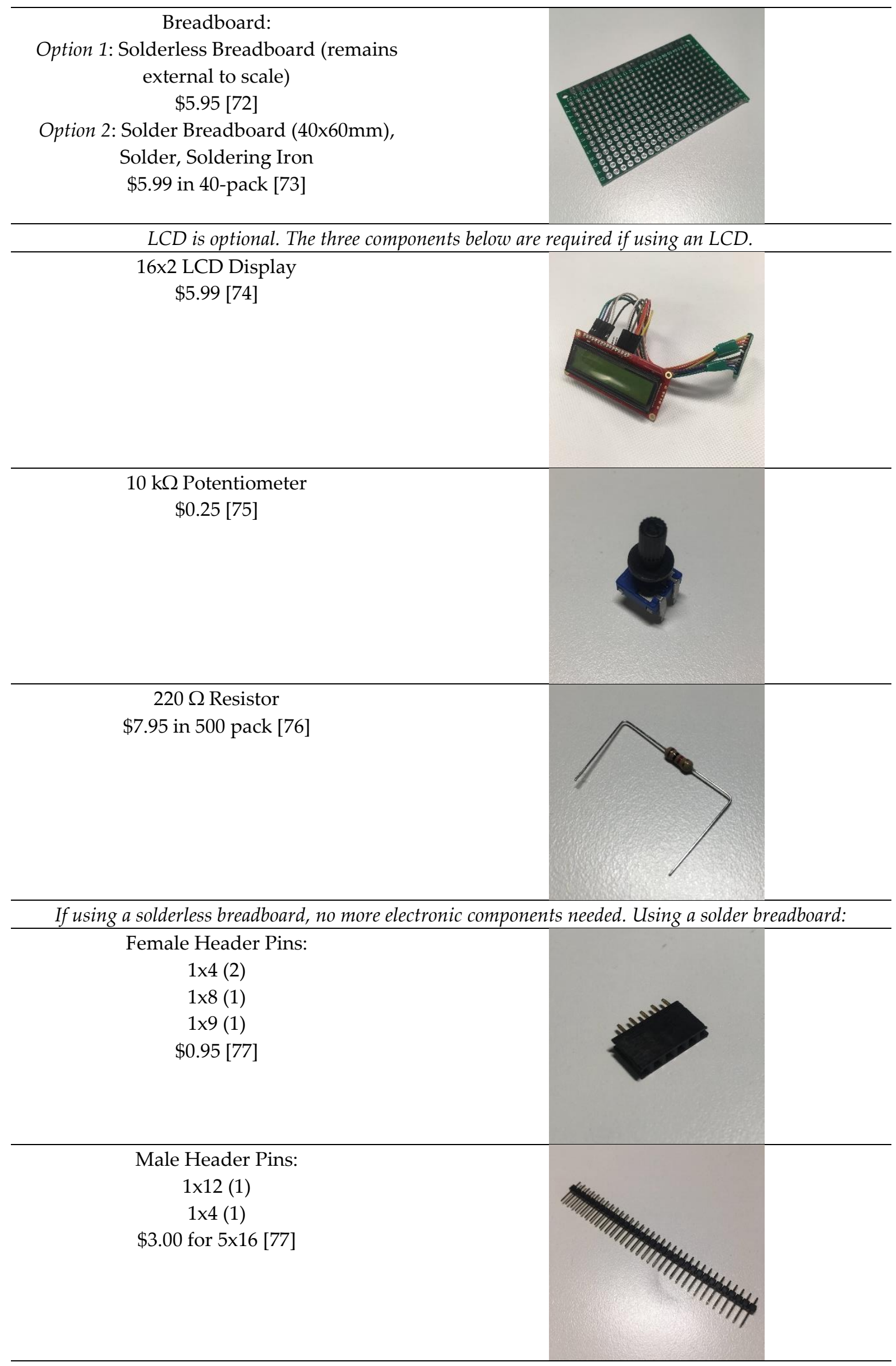




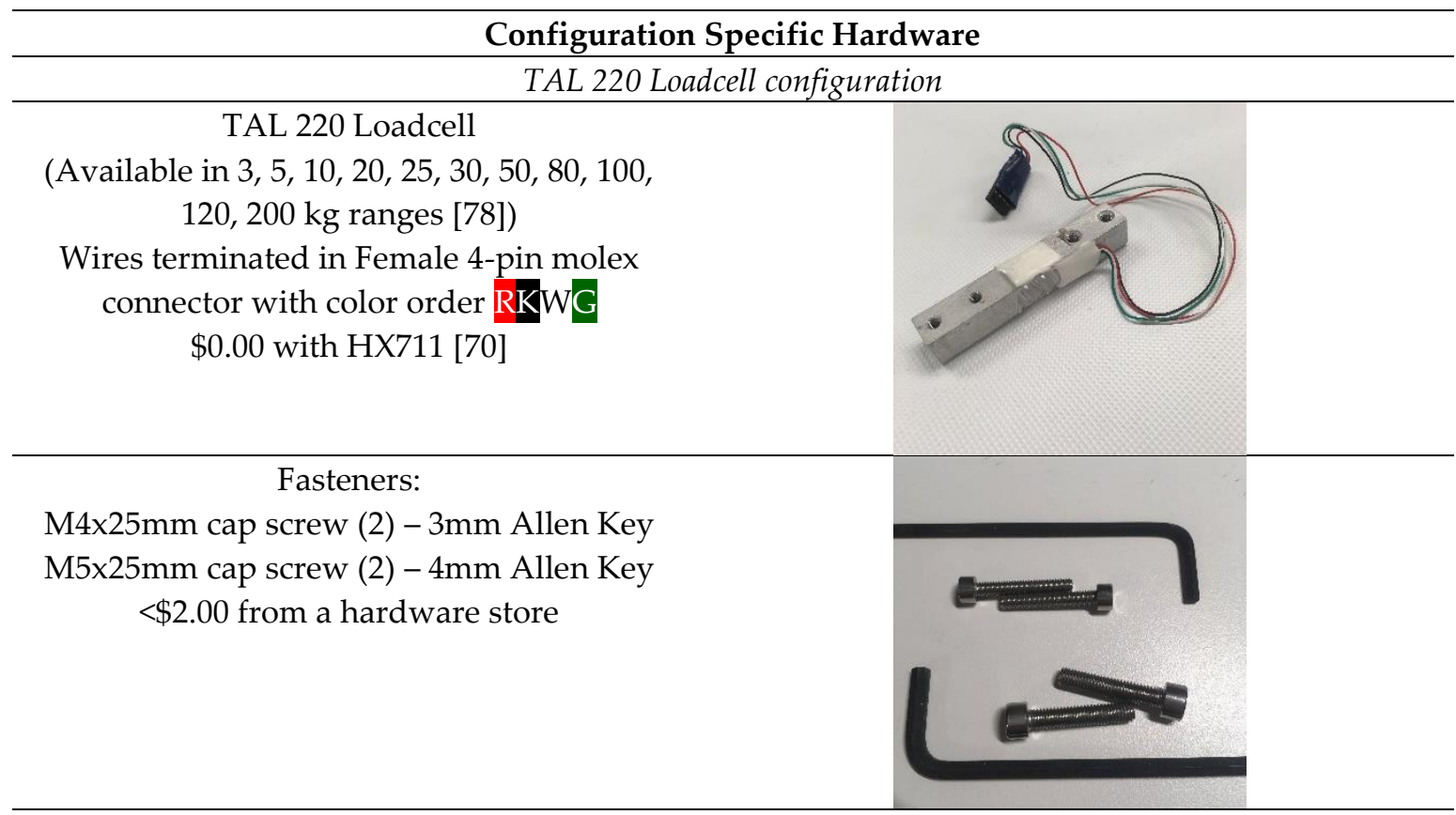

TAL 221 Loadcell configuration

TAL 221 Loadcell

(Available in 100, 150, 200, 300, 500, 750, 1000 , and $1500 \mathrm{~g}$ ranges [79])

Wires terminated in Female 4-pin molex connector with color order RKWG $\$ 8.95$ [80]

\section{Fasteners:}

M3x20mm cap screw (4) - 2.5mm Allen Key M3 nut (2) - 5.5mm Socket $<\$ 2.00$ from a hardware store

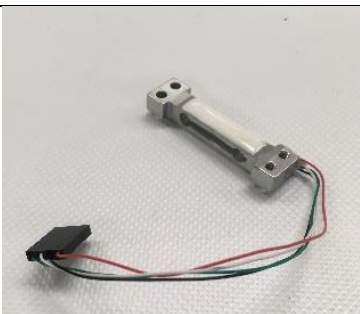

\subsection{Manufacturing and Assembly}

The 3-D printable components shown in Table 1 are available to be freely downloaded on the Open Science Framework (OSF) [81] and are released under a GNU General Public License (GPL) 3.0 [82]. All of the required STL-rendered components were 3-D printed polylactic acid (PLA), filament of diameter $2.85 \mathrm{~mm}$ on a Lulzbot TAZ 6 (Aleph Objects, Loveland CO). The objects were sliced with Cura Lulzbot edition v.3.6.20 [83] using the settings detailed in Table 2. The optional cover was 3-D printed translucent glycol modified polyethylene terephthalate (PETG) filament of diameter $2.85 \mathrm{~mm}$ on a Lulzbot TAZ 6 [84]. 
Table 2. Print Settings

Property

\begin{tabular}{lcc}
\hline Layer Height & $0.14 \mathrm{~mm}$ & $0.18 \mathrm{~mm}$ \\
\hline Wall Thickness & $2 \mathrm{~mm}$ & $1 \mathrm{~mm}$ \\
\hline Top/Bottom Thickness & $2 \mathrm{~mm}$ & $1 \mathrm{~mm}$ \\
\hline Infill & Cubic, $20 \%$ & N/A \\
\hline Support Material & Zigzag, Touching Bedplate \\
& Only, $30 \%, 50$ degrees & N/A \\
\hline Bed Adhesion & Skirt & Skirt \\
\hline Nozzle Temperature & $205{ }^{\circ} \mathrm{C}$ & $230{ }^{\circ} \mathrm{C}$ \\
\hline Print Speed & Infill: $40 \mathrm{~mm} / \mathrm{s}$, Wall: $30 \mathrm{~mm} / \mathrm{s}$, & Wall: $20 \mathrm{~mm} / \mathrm{s}$ \\
& Support: $60 \mathrm{~mm} / \mathrm{s}$ &
\end{tabular}

After printing the components, all support material and brims were cleaned from the components. Note that these components can all be printed without support material, depending on required surface finish.

The electronics were assembled according to the diagrams in Figures 1 and 2, which were created with Fritzing [85]. The LCD was wired based on Arduino documentation [86].

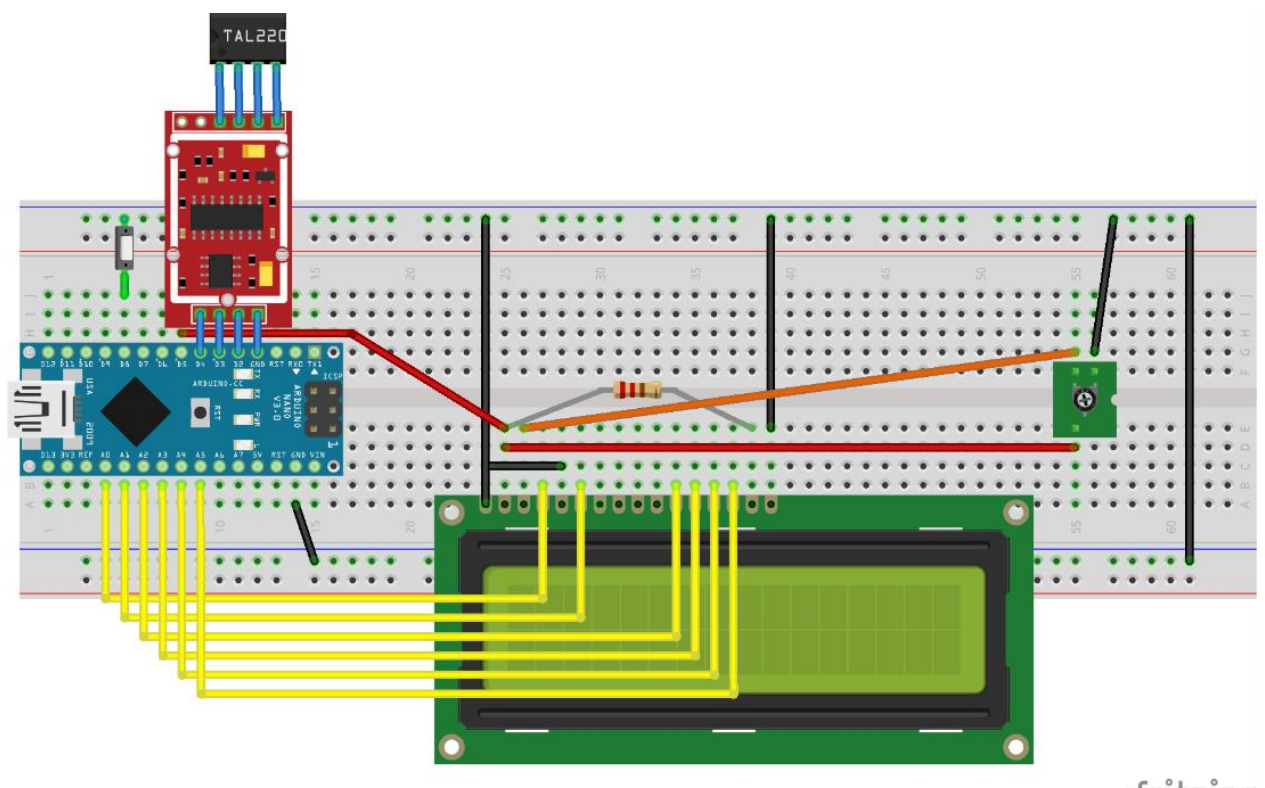

fritzing

Figure 1. Electrical circuit breadboard layout. Note that all components connected to and including the LCD are optional. 


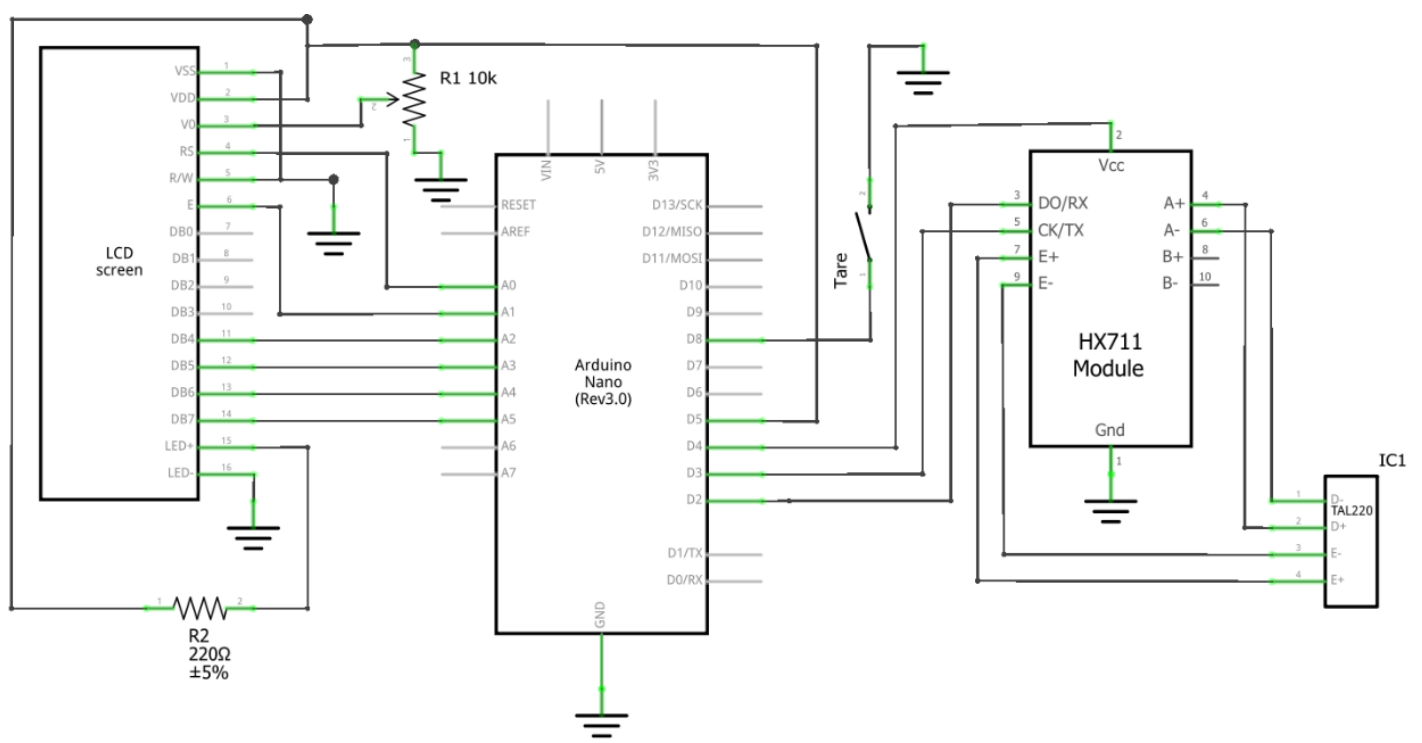

\section{fritzing}

Figure 2. Electrical circuit wiring diagram. Pinouts on the Arduino were selected to reduce the number of required jumper wires when using an Arduino Nano. Pinout selection can be modified in the firmware header file, Pinouts.hpp. Changing micro-controllers or pinouts may change the header pin requirements relative to the listing in Table 1.

After verifying functionality with a solderless breadboard, the components were installed on a $40 \times 60 \mathrm{~mm}$ solder breadboard as shown in Figure 3. In order to install the tare button on the face of the scale, a twisted pair was connected to the button pinouts and the button not immediately connected. The button was not connected to the twisted pair until after assembly. To allow for interchange of the PCBs, the LCD, and the loadcell, these were connected with header pins and jumper wires. The Arduino was purposefully placed to align with the slot on the side of the 3-D printed base for USB access when fully assembled.

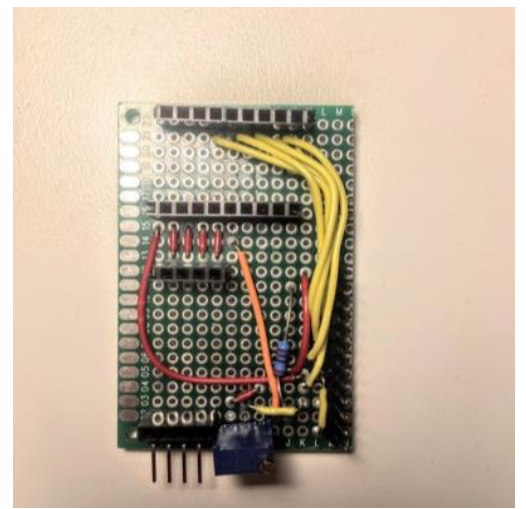

(a)

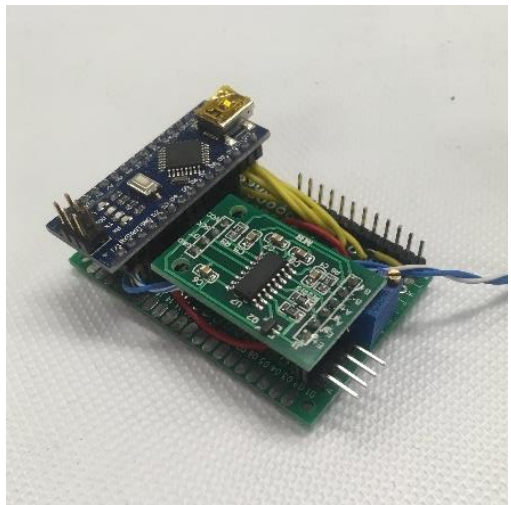

(b)

Figure 3. The circuit was assembled on a solder circuit board using jumper wires and header pins. The female header pins connect to the Arduino Nano and the HX711. The male header pins connect to the load cell and the LCD. The tare push button is attached via twisted pair to allow installation on the face of the scale. (a) The soldered components were arranged in such a way to minimize wire use and to properly place the Arduino when installed in the base. (b) Shows the final circuit board.

The 3-D printed base has several features to aid in assembly (Figure 4). The assembled circuit board was fit into the 3-D printed base - the base has bosses on the right side (facing the front) that 
locate the board and hold it in place when connecting and disconnecting a USB cable to the Arduino (Figure 5).

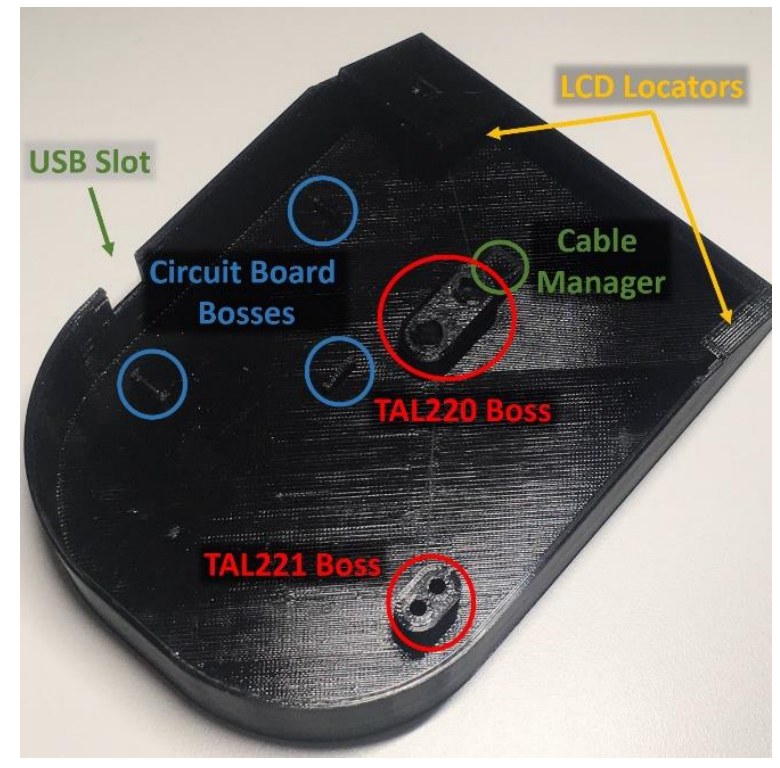

Figure 4. Key features of the base include standoffs to mount the load cell, locators for the screen and circuit board, and a slot for access to the Arduino Nano's USB port. The base also has a snap-seam to attach the cover to the base, enclosing the internal components.

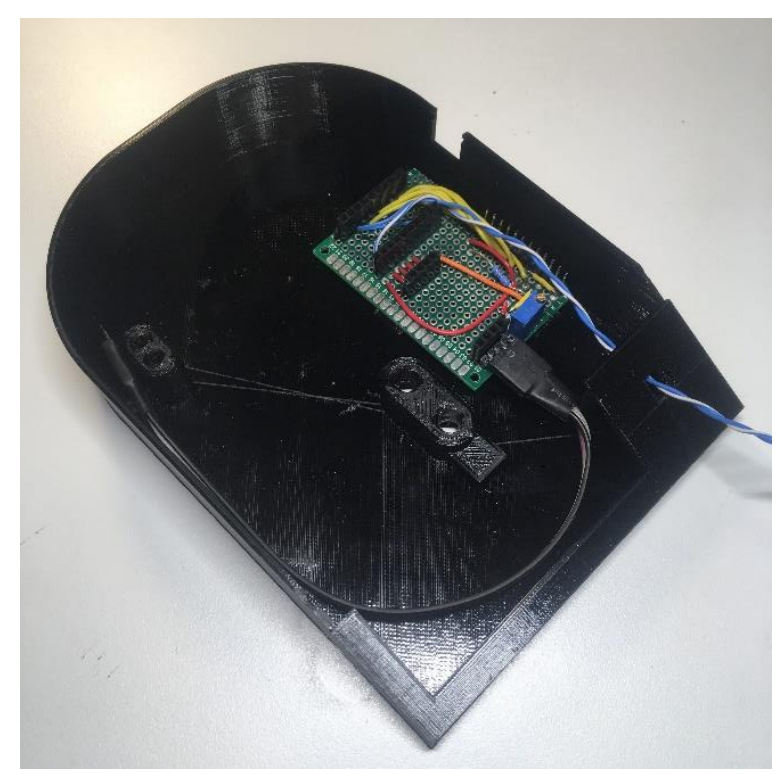

Figure 5. The circuit board fits into the bosses on the right side of the base to hold it in place. The twisted pair was fed through the hole for the push button and a set of female-male jumper wires were connected to the load cell header pins to reach the TAL221 wires.

The Arduino and HX711 were attached to their respective header pins. The LCD was placed in the locator slots on the front of the scale. The wires for the LCD were tucked under the cable manager on the TAL220 boss, then connected to the headers on the circuit board (Figure 6). The cable manager ensures that the wires from the LCD do not contact the loadcell, which would interfere with measurement accuracy. 


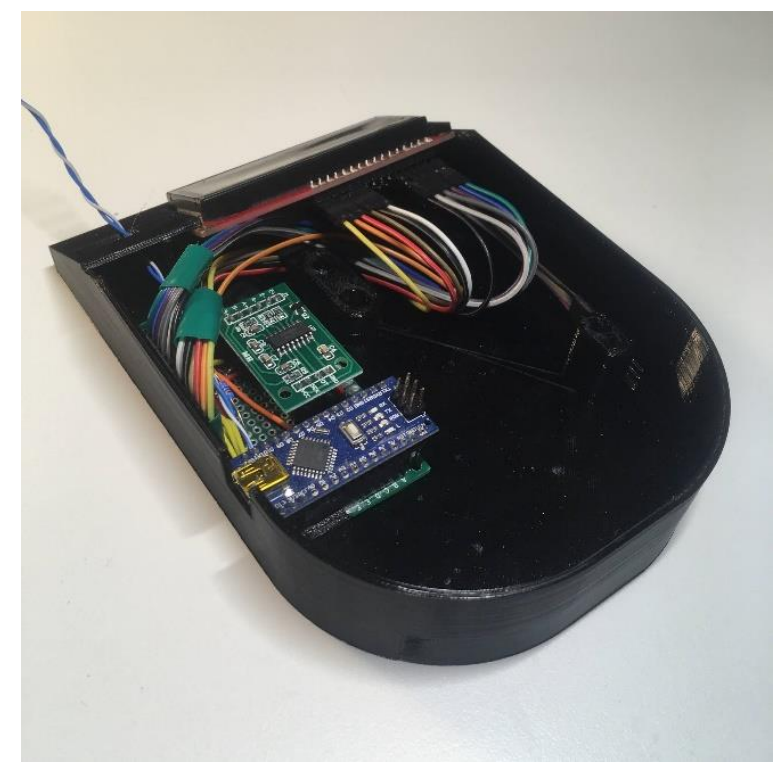

Figure 6. The LCD is held in place by two locators behind the slot for the screen. Its wires are tucked under a plastic wire manager attached to the TAL220 boss, then connected to the circuit board.

At this point the scale was powered on in order to set the potentiometer, which controls the contrast on the LCD. This can be set and then left alone. In order to do this, the Arduino was connected to a computer with the DigitalMassBalance firmware via USB. After uploading the firmware, a serial connection was opened to monitor the output from the microcontroller. The output indicates whether the scale has initialized correctly, informing the user as devices are powered on and checked. The LCD continuously displays the measured mass once powered on. The potentiometer was adjusted until the readout (number and unit) were easily visible on the LCD. In cases that the display appears non-functional, it should be checked in low light - if the screen does not appear backlit, no power is reaching the LCD. If it is receiving power, one of the jumpers is likely loose and all connections should be checked. SparkFun's LCD Hookup guide provides helpful and detailed troubleshooting suggestions if these checks do not work [87].

Prior to soldering the push button in place, the lead wire connections to the controller should be checked. With the controller powered on, the tare is checked by shorting the twisted pair - a dot display on the bottom right of the LCD appears when the pair is shorted, indicating proper communication. With that checked, the button can then be soldered and secured in place. A small amount of non-conductive glue may be used to keep the button in place.

After setting up the LCD, the loadcell was installed. The loadcell must be mounted so that its wires run toward the base-fixed end of the loadcell. The wires will interfere with measurement accuracy if running off of the floating end of the loadcell. The installation procedure depends on the loadcell style in use:

- TAL220: Install the M5 end (the wires run to this end) to the TAL220 boss on the base of the scale (Figure 7). Connect the loadcell to the HX711 pinouts - Red:E+, Black:E-, White:A-, Green:A+. Snap the cover onto the base - this fully encloses the electronics, offering some protection from thermal variations on the amplifier. Attach the bed to the loadcell using the M4 bolts. 


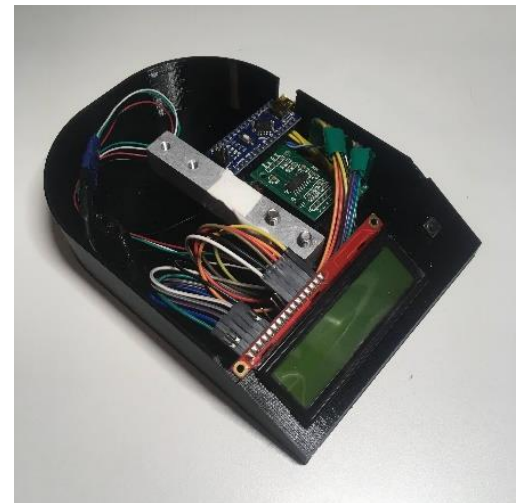

(a)

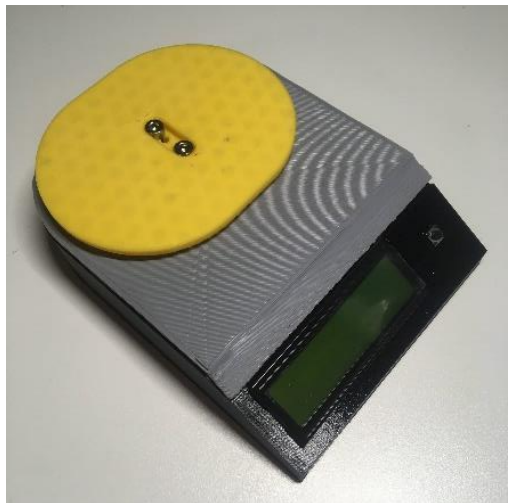

(b)

Figure 7. (a) The TAL221 loadcell should be installed with the wires leading off the end of the loadcell attached to the base - the M5 tapped holes. Note that the button is also installed. (b) After snapping on the lid, the bed can be attached to the free end of the load cell using two M4 bolts.

- TAL221: Sandwich the cover between the bed and the loadcell. Connect the untapped end of the loadcell (the wires do NOT run to this end) to the bed using M3 screws and nuts (Figure 8a). Connect the loadcell to the HX711 pinouts - Red:E+, Black:E-, White:A-, Green:A+. Finally, attach the tapped M3 end to the TAL221 boss on the base (Figure 8b). This fit is tight so the wires on the loadcell lead off the end fixed to the base.

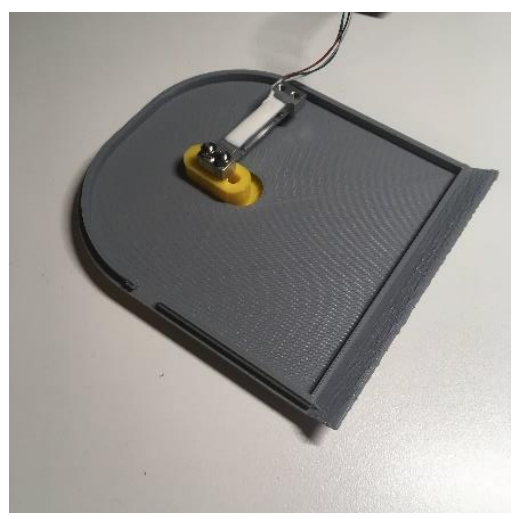

(a)

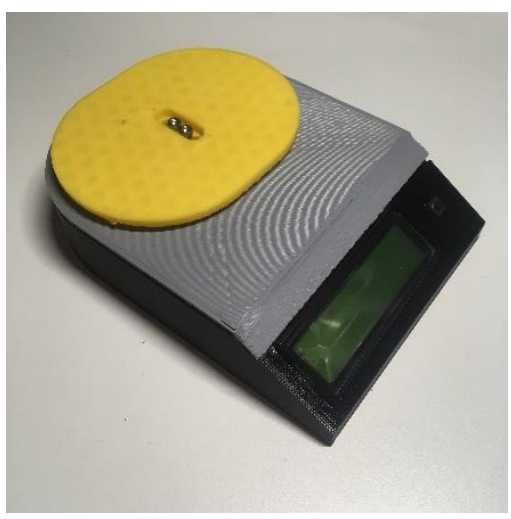

(b)

Figure 8. (a) The cover must be sandwiched between the loadcell and the bed prior to attaching to the base. Note the direction the loadcell is aimed so it will rest on the TAL221 boss when the cover is snapped on. (b) After connecting the loadcell to the controller, the cover is snapped on and the TAL221 is screwed to the base using two M3 bolts. This must be done by feel, but does not take very long.

\subsection{Firmware}

The firmware to drive the scale (called DigitalMassBalance) is also in the OSF repository [81]. A single installation contains functionality for both configurations of the scale (simple scale with digital display and lab scale with serial interface). The configuration header file, Config.hpp, can be modified to tell the controller whether an LCD is installed. Changing this setting determines whether the LCD will be initialized upon startup; and the serial interface listens by default as this has negligible effect on performance.

The firmware package makes use of two open source libraries: (1) the HX711 library by GitHub user bogde [88], used under the MIT License; and (2) the LiquidCrystal Library for Arduino by HansChristoph Steiner [89], used under the GNU Lesser General Public License. 
The HX711 library provides an interface with which to initialize, and read from, the HX711 loadcell amplifier. The HX711 library can provide raw (long integer with tare offset) or calibrated (scaled by a sensitivity value from unitless integer to mass with units) data. The library's built-in tare offset is used to implement zeroing of the scale (only the bed - no containers), while taring (subtracting a known mass from the reported value) is implemented in the firmware. Raw data is collected from the HX711 library in order to allow flexibility in the data averaging/filtering scheme used by the scale.

The LiquidCrystal library is used to write information to the LCD. Methods in the DigitalMassBalance firmware interface with the library, clearing the screen, moving the cursor, and writing information.

The DigitalMassBalance firmware itself is composed of a single Arduino source-code file, DigitalMassBalance.ino, which implements all methods and loops used during normal operation, plus three header files which organize definitions used by the firmware:

- Config.hpp contains configuration variables for the HX711, the LCD, and calibration and serial communication protocols.

- Libraries.hpp contains '\#include' statements for all the libraries used by DigitalMassBalance.

- Pinouts.hpp contains definitions for the location of hardware connections to the Arduino. These can be modified to accommodate the pinouts used in a particular setup.

Upon receiving power, the Arduino runs its setup loop, which completes six steps:

- Initialize a 9600 baud serial connection. The firmware is set to wait for serial communication to initialize before continuing. Note that this does not noticeably affect startup time when receiving power from a non-serial-enabled device (such as a $5 \mathrm{~V}$ power block or a battery).

- The HX711 undergoes a similar startup procedure, receiving power and ensuring proper communication. This is indicated by a series of readouts over serial.

- If an LCD is expected by the firmware (set in Config.hpp), the LCD is powered up. Once it is on, all digits of the display flash with the character ' 8 ' for less than a second. This initialization is also indicated by readouts over serial.

- With the hardware running, the Arduino checks its hard memory (EEPROM) for a saved calibration sensitivity (such a value is saved at the end of a calibration sequence). If one exists, the sensitivity is read and applied to the digital readout. If no sensitivity is saved, the scale defaults to a value of 1 , which just returns the raw measurement from the HX711. The read sensitivity value is reported over serial. This message completes unsolicited responses from the scale - all further communication from the Arduino result from commands sent over serial. A complete, successful initialization is shown in Figure 9.

- At the time of writing, a simple averaging window is used to stabilize measurements from the scale. Measurements are stored in a first-in-first-out (FIFO) queue whose size is set in Config.hpp. The size of this window affects the response time of the scale. During initialization, this queue is automatically cleared to an array of zeros.

- Finally, the tare button is set to an input in INPUT_PULLUP mode, which makes use of an internal pullup resistor. This setting saves component cost and makes the tare button active LOW. 


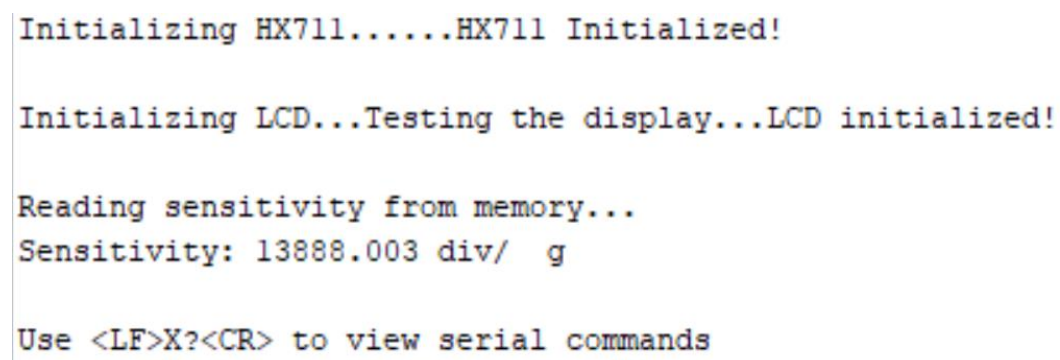

Figure 9. The scale returns a readout similar to the one shown during initialization. The readout indicates the action in progress, success, and returns the sensitivity value when reading from memory.

After completing setup, the Arduino enters a loop. With each iteration, the current mass measurement is retrieved from the HX711 and stored in the averaging queue, and the average mass is calculated and stored. This occurs as fast as the Arduino can process - there is no enforced sample rate for the mass. The Arduino also listens for serial input consistent with SMA SCP 0499 (detailed in section 2.5.2, which discusses the operation of the scale as a lab scale) [65]. At the same time, it displays the current averaged mass measurement on the LCD and checks for a press of the tare button. These listening and reporting actions are completed at an enforced refresh rate (set in Config.hpp). This is done to visually stabilize (slow down) the LCD output and to enforce the rate at which data is reported over serial.

\subsection{Operation of Design}

The scale is designed for two forms of interaction: (1) as a simple scale with LCD output and push-button interaction and (2) as a lab scale with a serial interface to allow data logging and advanced control of the scale.

\subsubsection{Simple Scale}

For simple use, the scale is connected to power over USB to a $5 \mathrm{~V}$ power block, such as that used to charge a cellphone. Alternatively, $5 \mathrm{~V}$ power can be provided to the Arduino 5V and GND pins through other means. Possible interactions are:

- Tare: A press and release of the push-button on the front of the device will tare the scale to the current weight. The push-button is acknowledged when closed (pushed) by a dot on the lower right-hand corner of the LCD.

- Calibrate: Pressing and holding the push-button for 3 seconds (the wait time is adjustable in Config.hpp) will initialize a calibration sequence using the calibration mass set in Config.hpp. The scale will tare, then indicate the mass to apply to the bed. After detecting an added mass, the scale will measure the mass for 10 averages, then calculate the new scale sensitivity and save it to EEPROM.

\subsubsection{Lab Scale with Serial Interface}

The scale's 9600 baud serial interface has been designed to Level \#2 compliance with the SMA Scale Communication Protocols [65]. This includes the six specified Level \#1 commands, plus additional commands. The full command list is detailed below, listing the command name, command character (indicated $<$ char $>$ ), followed by a brief description where necessary. All command characters must follow a linefeed $\langle\mathrm{LF}\rangle$ and precede a carriage-return $\langle\mathrm{CR}\rangle$. Full details of the response format and communication protocol are available in SMA SCP-0499 [65].

- $\quad$ Return displayed weight $\langle\mathbf{W}\rangle$.

- Zero the scale $<\mathbf{Z}>$.

- Run scale diagnostics $<\mathrm{D}>$. This is specified by SMA to check for memory or calibration errors. 
- Return 'about' information for the scale $\langle\mathrm{A}\rangle,\langle\mathrm{B}\rangle$. These are specified by SMA to return information about the scale's compliance level and firmware information.

- Reset the scale $<$ ESC $>$.

- Continuously report weight $<\mathbf{R}>$. Returns weight at the read rate until another command is received.

- Tare the scale $<T>$. This is different from zeroing in that the tare is for, as an example, ignoring the mass of a container. Meanwhile, zero is intended to set 'zero' for the scale with nothing on the bed.

- Clear the current tare $<\mathrm{C}>$. This sets the tare weight to zero, causing further readouts to reference to the zero set by $<\mathrm{Z}>$

- $\quad$ Return the tare weight $<\mathbf{M}>$.

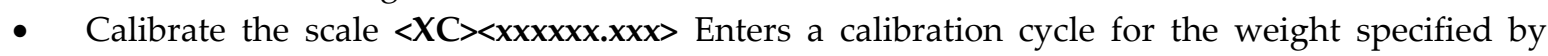

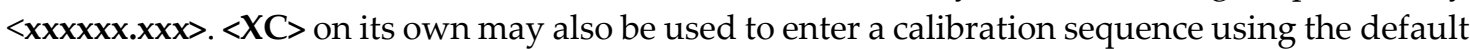
calibration mass set in Config.hpp

- Toggle power to the $\mathrm{LCD}<\mathrm{XL}>$. This changes the power state of the LCD, either turning it off or reinitializing it. This can be used for power savings when the display is not needed.

- Scroll output precision $\langle\mathbf{X P}\rangle$. This scrolls the number of digits on the readout between 0 and 4 .

- List possible commands $<X$ ? $>$. This lists the recognized commands for the user. Since the leading $X$ (required by SMA SCP 0499) is non-intuitive, it is indicated at the completion of the setup loop (Figure 9).

\subsection{Validation}

The 3-D printed open source scale was tested against two proprietary laboratory-grade scales in order to check the functionality, accuracy, and linearity of the scale. The open source scale was tested for three loadcells: 1) a 5kg TAL220 loadcell, 2) a 500g TAL221 loadcell and 3) a 100g TAL221 loadcell. TAL220 and TAL221 refer to the shape of the load cell. The mass range is determined by the size of the cutout in the middle of the loadcell where the less material left behind the more sensitive/lower the mass range.

\subsubsection{Laboratory-grade scale comparison}

The open source scale was tested against a Denver APX402 400/0.01g digital mass balance and a Denver A-160 160/0.1mg digital analytical balance [90,91]. The A-160 was calibrated 2 months prior to the first round of testing. Due to limitations in the range of the two proprietary lab-grade balances, neither loadcell was tested to the full range in this scale. The APX402 and the open source scale were tested up to $300 \mathrm{~g}$. The A-160 and the open source scale TAL221 were tested up to $150 \mathrm{~g}$. However, rigorous testing of the loadcells themselves, was not the purpose of this testing - the results of such testing are documented in the manufacturer data sheets for loadcells and the loadcell amplifier [63; 78-79].

In order to calibrate the scale, a container was measured on the A-160. Using the measured mass (reported down to $0.1 \mathrm{mg}$ ) as a reference value, the scale was put into calibration mode. The scale tared itself, then waited for the reference mass to be added. Once added, the scale took a total of 100 averaged measurements over the span of several seconds in order to determine the sensitivity of the loadcell (i.e. calibration value that multiplies a raw value to obtain a value with units).

The tests were completed using a light container with sand incrementally added. The container was placed on the APX402 scale, but not tared. Sand was added to the container until a desired mass was achieved. The container of sand was then massed on the APX402, the A-160, and the scale, in that order. After the upper limit of the A-160 was reached (160g), the APX402 and open source scale were still tested until the upper limit of the APX402 (around 330g). The A-160 has a glass case, which was closed while taking measurements. The APX402 and the open source scale did not have any cases to protect from airflow interference. Measurements were repeated 5 times for each increment of mass in order to check the repeatability of measurements (precision). 
In order to compare the measurements amongst the three scales, two measures were computed. First is the standard deviation of the measurements at each discrete mass. This was computed for each individual scale to offer comparison on the stability of their readouts, indicating the precision of each instrument. Second, in an attempt to quantify the accuracy of the scale, its average measurement for each discrete mass up to $160 \mathrm{~g}$ was compared to the average measurement of the A160 (the device used to calibrate it) using the absolute value of the difference between the two. The differences offer some perspective on how closely the open source scale tracked with the proprietary lab-grade scales.

\subsubsection{Self calibration of open source scale for 100g TAL221}

Often a developer of open hardware may only have access to a calibrated scale initially, so it is important to be able to calibrate the open source scale from previous measurements (e.g. selfcalibration). To demonstrate this the 100g TAL221 was tested against the previously tested (calibrated) $500 \mathrm{~g}$ TAL221.

Four containers were filled to nominal masses of $25,50,75$, and $100 \mathrm{~g}$ as measured on the $500 \mathrm{~g}$ TAL221. These new masses can be considered secondary standards as their masses are known to the accuracy of the $500 \mathrm{~g}$ TAL221. After measuring all 4 masses 5 times on each scale, the 100g TAL221 was installed on the open source scale. It was calibrated using the $75 \mathrm{~g}$ mass. All 4 masses were then measured 5 times on the 100g TAL221. The resulting data was processed in the same manner as the other two tests, except average differences are referenced to the 500g TAL221 loadcell.

\subsection{Economic Analysis}

In order to determine the costs of the various versions of the open source digital scale, the 3-D printable components were massed on another digital scale $+/-0.01 \mathrm{~kg}$. The total cost $\left(T_{c}\right)$ of the apparatus can be determined by

$$
\mathrm{Tc}=\mathrm{V}+\mathrm{mCe}+\mathrm{mCp}
$$

Where $V$ is the cost of the vitamins (or non-digitally manufactured components listed in Table 1), $m$ is the mass of all the 3-D printed parts (e.g., all the STL rendered parts in Table 1); $C_{e}$ is the cost of the electricity per $\mathrm{kg}$ to print; and $C_{p}$ is the cost of plastic per $\mathrm{kg}$. The Lulzbot Taz 6 uses approximately $9.11 \mathrm{kWh}$ per $\mathrm{kg}$, as measured by a multimeter $+/-0.01 \mathrm{kWh}$ and reported previously [92]. The average cost of electricity in the U.S. is about $\$ 0.1029 / \mathrm{kWh}$ [93]. The cost of the PLA filament from Lulzbot was U.S. \$20/kg [94].

\section{Results}

\subsection{Laboratory grade scale comparison}

Repeatability testing on the 5kg TAL220 loadcell yielded a standard deviation of $0.0163 \mathrm{~g}$ on average ( $\max 0.0288 \mathrm{~g}$ ), as compared to $0.0035 \mathrm{~g}$ for the APX402 and $0.0002 \mathrm{~g}$ for the A- 160 . The average absolute difference between the open source scale and the A-160 was $0.0363 \mathrm{~g}$. The standard deviation and absolute differences are plotted for each discrete mass in Figures 10a and 10b, respectively. 


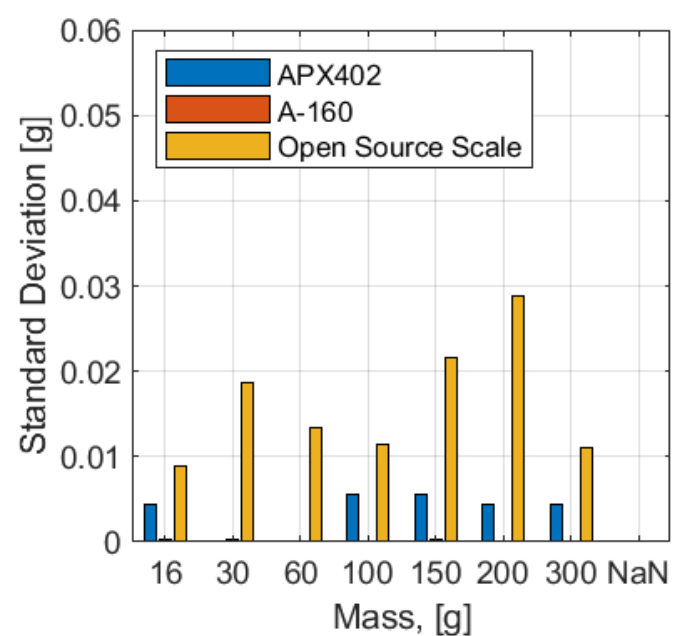

(a)

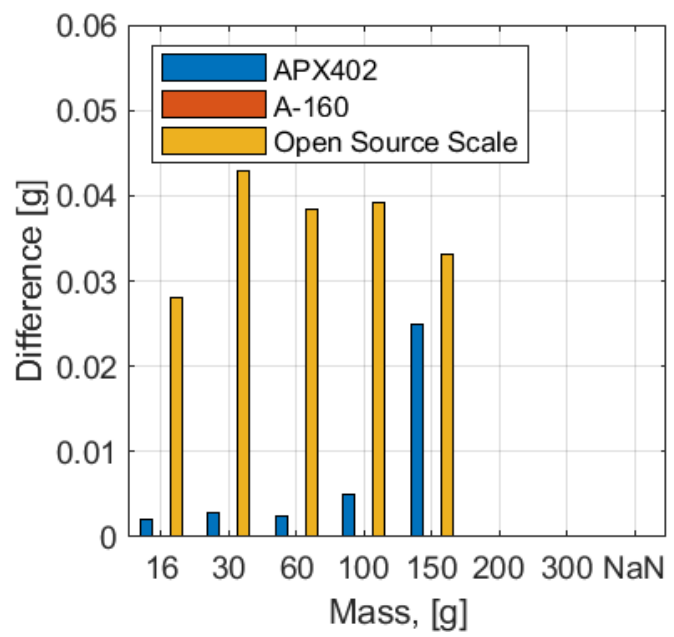

(b)

Figure 10. The $5 \mathrm{~kg}$ loadcell results are shown (a) The standard deviation (sample of 5 measurements) averaged to $0.0163 \mathrm{~g}$. This is large relative to the APX402 and the A-160; (b) The absolute value of the difference between each scale and the A-160 is shown. The open source scale averaged a difference of $0.0363 \mathrm{~g}$.

Testing conducted on the 500g TAL221 loadcell yielded a standard deviation of $0.0207 \mathrm{~g}$ on average $(\max 0.0521 \mathrm{~g}$ ), as compared to $0.0043 \mathrm{~g}$ for the APX402 and $0.0027 \mathrm{~g}$ for the A-160. The average absolute difference between the open source scale and the A-160 was $0.0142 \mathrm{~g}$. The standard deviation and absolute differences are plotted for each discrete mass in Figures 11a and 11b, respectively.

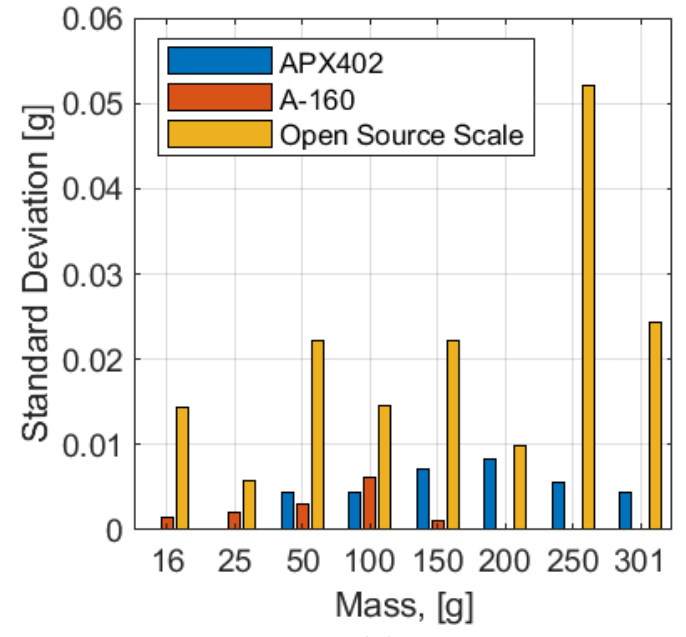

(a)

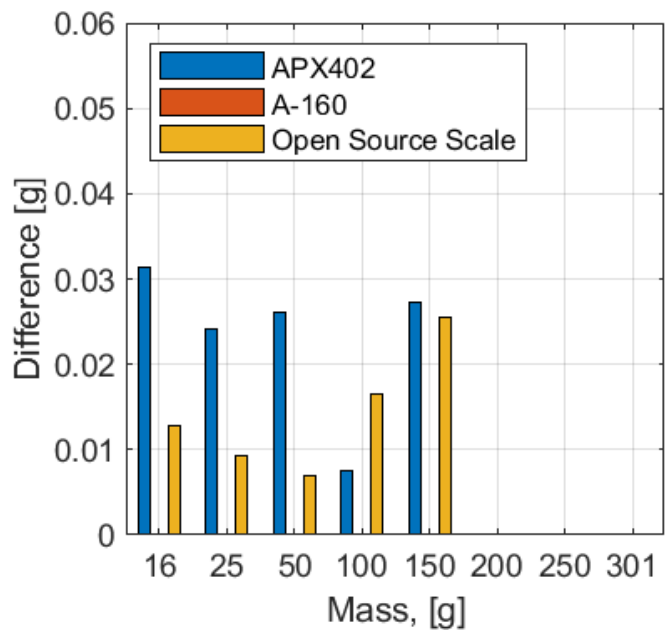

(b)

Figure 11. The $500 \mathrm{~g}$ loadcell test results are shown. (a) The standard deviation (sample of 5 measurements) averaged to $0.0207 \mathrm{~g}$ for the open source scale. This is large relative to the lab-grade scales; (b) The absolute value of the difference between the average measurements by the A-160 and the other two scales are shown. The open source scale average measurement was within $0.0142 \mathrm{~g}$ of the A-160, on average.

The testing completed on the TAL221 500g loadcell followed the same procedures, but the conditions appear to have been different. The A-160's standard deviation was an order of magnitude higher than during testing of the TAL220, and the difference between the APX402 and the A-160 was 5 times larger, on average. It is expected that the environment had some effect on testing - it is possible that HVAC could have affected measurements by increasing airflow on the scales. It may 
also be the case that the scales were not properly pre-warmed (powered on for 15 minutes to an hour) prior to the initiation of testing.

Finally, testing conducted on the $100 \mathrm{~g}$ TAL221 yielded a standard deviation of $0.005 \mathrm{~g}$ on average (0.0066g max). This is around $20-50 \%$ higher than the standard deviation measured for the APX402 during the two rounds of testing detailed above, indicating the $100 \mathrm{~g}$ loadcell offers precision on the order of (though slightly lesser than) the APX402. The average difference between the $100 \mathrm{~g}$ and $500 \mathrm{~g}$ TAL221 loadcells was $0.0198 \mathrm{~g}$ on average, though the average difference here should not be taken alone to certify the accuracy of the $100 \mathrm{~g}$ loadcell, as there is unquantified error propagation between the calibration of the $500 \mathrm{~g}$ and $100 \mathrm{~g}$ loadcells. This is the limitation of using the open source scale to make secondary calibrated masses. The error propagation is a result of the calibration of the $100 \mathrm{~g}$ TAL221 against the 500g TAL221, rather than the A-160. The test results are shown in Figure 12.

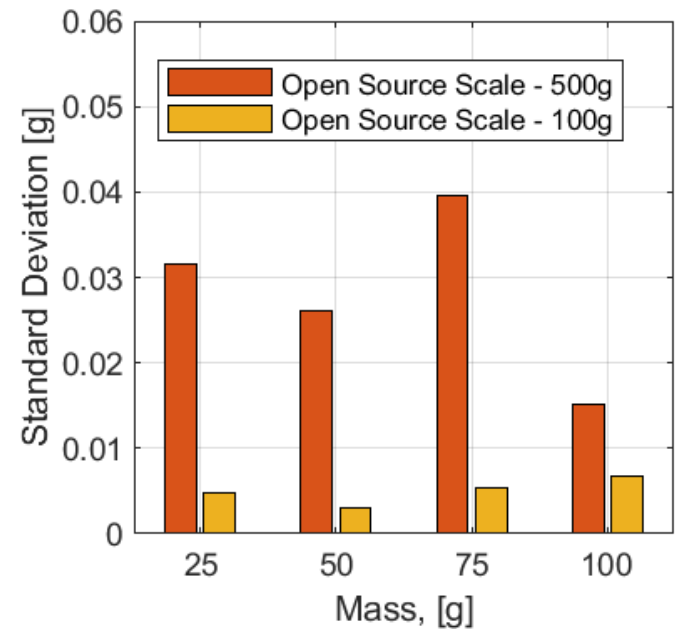

(a)

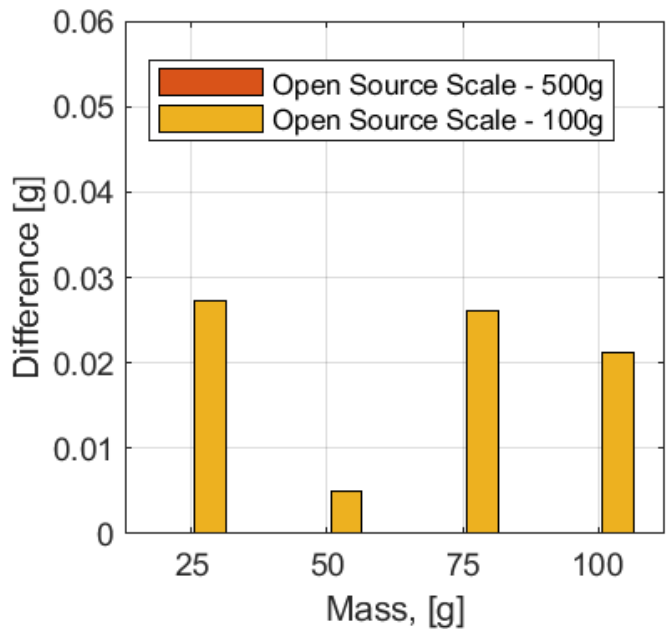

(b)

Figure 12. The $100 \mathrm{~g}$ loadcell test results are shown. (a) The standard deviation (sample of 5 measurements) averaged to $0.005 \mathrm{~g}$ for the open source scale. This is close to that of the lab-grade scales (on the same order as the APX402); (b) The absolute value of the difference between the average measurements by the 500g TAL221 and the other two scales are shown. The 100g TAL221 average measurement was within $0.0198 \mathrm{~g}$ of the $500 \mathrm{~g}$ TAL221, on average.

These tests showed that the scale tracks linearly with the two lab-grade scales, but its output is less precise. The precision of the scale is a function of the range and style of the loadcell. These results support the idea that smaller range loadcells produce more precise measurements, with the $100 \mathrm{~g}$ TAL221 approaching the precision of the APX402. The average standard deviation $(\sigma)$ of each loadcell tested is compared to its range in Table 2 as a percentage $\left(\% F S=\frac{\sigma}{\text { range }} \cdot 100\right)$.

Table 2. The average standard deviation for each loadcell during testing is compared as a percentage of the loadcell's total range. These results suggest that the precision of the loadcell is a function of its range and style.

\begin{tabular}{ccc}
\hline Style/Range & $\boldsymbol{\sigma}$ & \%FS \\
\hline TAL220/5000g & 0.0163 & $0.0004 \%$ \\
TAL221/500g & 0.0207 & $0.0041 \%$ \\
TAL221/100g & 0.0050 & $0.0050 \%$ \\
\hline
\end{tabular}

The only loadcell tested to its full range was the 100g TAL221 because of its smaller range and the results indicate linear behavior of the loadcell across its entire range of measurement.

\subsection{Economic Analysis}

The total mass of the 3-D printed components is $m=18.74 \mathrm{~g}+33.22 \mathrm{~g}+65.44 \mathrm{~g}=117.40 \mathrm{~g}$, bringing the cost of printed components to $\$ 2.46$. Assuming no components are previously owned, the total 
investment (buying bulk items) for the basic scale is $\$ 48.90$ ( $\$ 28.66$ if using an Arduino derivative [67]), plus $\$ 14.19$ to add an LCD, and $\$ 4.00$ to use a wall outlet for power. Accounting for the value of individual components from within bulk purchases, the cost of the scale is $\$ 38.29$ ( $\$ 18.05$ with derivative), plus $\$ 6.26$ for an LCD and $\$ 4.00$ to use a wall outlet for power. These results are summarized in Table 2. These estimates do not account for taxes or the cost of shipping, jumper wires, or solder.

Table 3. The cost of the scale varies based on configuration and initial investment. Using a wall outlet for power (as opposed to a computer) costs an extra $\$ 4.00$.

\begin{tabular}{ccc}
\hline Configuration & $\begin{array}{c}\text { Total } \\
\text { Investment }\end{array}$ & $\begin{array}{c}\text { Cost Corrected for } \\
\text { Bulk Purchases }\end{array}$ \\
\hline No LCD & $\$ 51.36 / \$ 31.12^{1}$ & $\$ 40.75 / \$ 20.51$ \\
LCD & $\$ 65.55 / \$ 45.31$ & $\$ 47.01 / \$ 26.77$ \\
\hline
\end{tabular}

${ }^{1}$ Second value uses Arduino derivative

\section{Discussion}

\subsection{Open Source Scale for Distributed Manufacturing}

The open source scale showed linearity consistent with data sheet claims during testing. The precision of the loadcell is dependent on the type and range of the loadcell, meaning that precision requirements should inform decision making during loadcell selection. All three loadcells tested provide repeatability finer than $0.1 \mathrm{~g}$. A major limitation to the scale is that it is susceptible to environmental effects such as temperature. Documentation from Denver Instruments suggests that powering on the scale for $15+$ minutes prior to testing helps stabilize its output by allowing the components to reach a steady-state temperature [90-91]. This was observed during testing, but not specifically tested. Temperature variations on the HX711 were limited by enclosing the amplifier to reduce airflow, and could be further improved by introducing a temperature sensor to make corrections for environmental variations.

A significant advantage of this scale is that its range and precision is interchangeable to meet varying needs. The serial interface offers the possibility to log data and control the scale during testing, allowing partially and fully automated testing. The open-source nature of the scale makes room for improvement and modification where necessary to meet particular needs. Additionally, the modular nature of its design allows for cost savings by removing un-needed components, such as the LCD in the case of automated/computer-based measurement.

The two proprietary, lab-grade scales that were used for comparison testing are out of production. The best estimate for their cost is listings on eBay, which price the APX402 at $\$ 75.00$ and the A-160 at $\$ 425.00[95,96]$. Both lab scales offer RS232 serial interfaces over which the scale can be controlled and interrogated, similar to the open source scale. This means that a scale of comparable (although still lesser) precision to the APX402 can be constructed for as low as one-third of the cost of used eBay purchases. New scales with comparable capability to the open source scale come at varying costs, depending on their range, precision, and the presence of a serial interface. Some readily available options are compared to the open scale in Table 4 . The percent savings $\left[\frac{(\text { os-commercial })}{\text { commercial }}\right]$ achieved by using the open source scale are calculated and summarized in Table 4 . As can be seen by Table 4 it is possible to purchase a less expensive scale without serial capability (in this case a kitchen scale), but that there are substantial savings using the open source approach for scales with serial capability. For lab-grade scales the open source scale saves between $57 \%$ and $83 \%$ from the commercially available scales. 
Table 4. Several proprietary scales listed online were compared in price and capability to the open source scale. This was done to indicate the cost savings allowed by the open source scale, which vary greatly depending on the functionality and range desired.

\begin{tabular}{cccc}
\hline Range/Repeatability & $\begin{array}{c}\text { Serial } \\
\text { Capability }\end{array}$ & Retail Cost & $\begin{array}{c}\text { Percent Savings of } \\
\text { Open Source Scale } \\
\mathbf{( \$ 4 7 . 0 1 )}\end{array}$ \\
\hline $500 \mathrm{~g} / 0.01 \mathrm{~g}[97]$ & No & $\$ 15$ & $\mathrm{NA}$ \\
$500 \mathrm{~g} / 0.1 \mathrm{~g}[98]$ & No & $\$ 88$ & $-47 \%$ \\
$5000 \mathrm{~g} / 0.1 \mathrm{~g}[99]$ & No & $\$ 55$ & $-15 \%$ \\
$300 \mathrm{~g} / 0.001 \mathrm{~g}[100]$ & Yes & $\$ 253$ & $-81 \%$ \\
$500 \mathrm{~g} / 0.002 \mathrm{~g}[101]$ & Yes & $\$ 115$ & $-59 \%$ \\
$600 \mathrm{~g} / 0.01 \mathrm{~g}[102]$ & Yes & $\$ 110$ & $-57 \%$ \\
$5000 \mathrm{~g} / 0.08 \mathrm{~g}[103]$ & Yes & $\$ 289$ & $-83 \%$ \\
\hline
\end{tabular}

In addition, to the benefits of greater control, data logging, customization and cost the open source scale has several other advantages. There are often artificial barriers to obtaining scientific equipment in various countries. First, there are often tariffs, duties, "made in \{specific country\}" restrictions, and taxes added to importation of scientific equipment. These can combine with other factors like cost to limit research, medical care and educational opportunities (particularly in the developing world), which hampers economic development [104-106]. By being able to fabricate a digital scale from low-cost base components, most of which are widely available, scientists, educators, and medical staff can avoid these additional costs and gain access to the tool. Secondly, the most extreme cases, when countries are in desperate need for a wide range of medical/scientific equipment such as currently underway during the COVID-19 pandemic [107], there are even export bans [108] that would limit scientific access to tools. Personal fabrication overcomes such bans. Third, arbitrary definitions of "equipment" rather than "supplies" [109] can limit a scientists' ability to spend money in the way their research demands. Again, being able to build equipment from supplies offers scientists more flexibility to obtain tools even in the face of administrative restrictions.

\subsection{Future Technical Work}

Documentation in the A-160 and APX402 manuals suggest that leaving the scale on for 15-60 minutes prior to testing will aid in the accuracy and repeatability of measurements by allowing the components to warm up to a stable temperature. This was not done during the documented testing as for the majority of laboratory work such actions are unnecessary and may not be conducive to realworld use cases. This can, however, be tested in future development by logging mass and tracking room and component temperatures for long periods of time. Other methods for stabilizing the readout to temperature variations should also be explored. SparkFun's OpenScale microcontroller implements temperature sensing to correct for temperature and this implementation could be quantified [110].

The data logging/serial interface capability is currently restricted to a scale that is connected to a computer. The scale could be extended to allow automated serial logging using a device such as SparkFun's OpenLog, which stores serial output to an SD card [111]. This, in combination with battery power, would result in a portable logging scale for use in a variety of environments.

Testing should be conducted to determine the viability of this scale for use in long-term mass studies. Observations during the documented testing show that the scale tends to drift significantly when first turned on. This drift appears to be largely related to temperature, but may be related to other factors, such as loadcell creep [61]. The design could also be tested/modified to work with higher capacity loadcells. High-weight scales can approach $\$ 1,000$ in cost, but this open source scale could be modified to handle larger weight ranges without much cost increase [79, 112]. In addition, because the code is freely shared it can be integrated into more complicated systems such as feedback loop additive manufacturing, melt flow index and dynamic off-gassing experiments. In completing 
further testing, multiple scales should be constructed to test multiple load cells simultaneously, offering more consistent test conditions and results.

\section{Conclusions}

This study provided designs for a low-cost, easily replicable open source lab-grade precision digital scale. The designs are released under open source licenses to enable any lab or individual fabricate it using open source 3D printers and widely available low-cost components. Over several versions of the design with different load cells the open source scale was found to be repeatable within $0.1 \mathrm{~g}$, with even better precision depending on the load cell range and style. The scale tracks linearly with proprietary lab-grade scales, meeting the performance specified in the loadcell data sheets, indicating that it is accurate across the range of the loadcell installed. The scale can be produced at significant cost savings compared to scales of comparable range and precision when serial capability is present. The cost savings increase significantly as the range of the scale increases. The ability to use the same hardware and firmware for a variety of loadcells also makes the scale flexible to time-varying needs in a laboratory setting.

Supplementary Materials: Use video: MOST OS Balance v1.mpeg

Author Contributions: Conceptualization, B.R.H. and J.M.P.; methodology, B.R.H. and J.M.P.; software, B.R.H.; validation, B.R.H.; formal analysis, B.R.H. and J.M.P.; investigation, B.R.H. and J.M.P.; resources, J.M.P.; data curation, B.R.H.; writing - original draft preparation, B.R.H. and J.M.P.; writing - review and editing, B.R.H. and J.M.P.; visualization, B.R.H.; funding acquisition, J.M.P.

Funding: This research was funded by Aleph Objects and the Richard Witte Endowment.

Acknowledgments: The authors would like to thank P. Heiden and A. Patil for technical assistance and use of equipment.

Conflicts of Interest: The authors declare no conflicts of interest. The funders had no role in the design of the study; in the collection, analyses, or interpretation of data; in the writing of the manuscript; or in the decision to publish the results.

\section{References}

1. Fogel, K. Producing Open Source Software: How to Run a Successful Free Software Project; O'Reilly Media, Inc., 2005; ISBN 978-0-596-55299-2.

2. Webert, S. The Success of Open Source; Harvard University Press, 2004; ISBN 978-0-674-01292-9.

3. Gibb, A. Building Open Source Hardware: DIY Manufacturing for Hackers and Makers; Pearson Education, 2014.

4. Ackerman, J.R. Toward open source hardware. U. Dayton L. Rev. 2008, 34, 183-222.

5. Pearce, J.M. Building research equipment with free, open-source hardware. Science 2012, 337, 1303-1304.

6. Pearce, J. Open-Source Lab: How to Build Your Own Hardware and Reduce Research Costs; Elsevier; New York, 2013.

7. Da Costa, E.T.; Mora, M.F.; Willis, P.A.; Lago, C.L. do; Jiao, H.; Garcia, C.D. Getting started with openhardware: Development and control of microfluidic devices. Electrophoresis 2014, 35, 2370-2377.

8. Von Hippel, E. Democratizing innovation: The evolving phenomenon of user innovation. JfB 2005, 55, 6378.

9. Powell, A. Democratizing production through open source knowledge: From open software to open hardware. Media Cult. Soc. 2012, 34, 691-708.

10. Blikstein, P. Digital fabrication and "making" in education: The democratization of invention. FabLabs Mach. Mak. Invent. 2013, 4, 1-21.

11. Gershenfeld, N. Fab: The Coming Revolution on Your Desktop--from Personal Computers to Personal Fabrication; Basic Books, 2008; ISBN 978-0-7867-2204-4.

12. Wittbrodt, B.T.; Glover, A.G.; Laureto, J.; Anzalone, G.C.; Oppliger, D.; Irwin, J.L.; Pearce, J.M. Life-cycle economic analysis of distributed manufacturing with open-source 3-D printers. Mechatronics 2013, 23, 713726.

13. King, D.L.; Babasola, A.; Rozario, J.; Pearce, J.M. Mobile Open-Source Solar-Powered 3-D Printers for Distributed Manufacturing in Off-Grid Communities. Challenges in Sustainability 2014, 2, 18-27.

14. Wittbrodt, B.; Laureto, J.; Tymrak, B.; Pearce, J. Distributed manufacturing with 3-d printing: A case study of recreational vehicle solar photovoltaic mounting systems. J. Frugal Innov. 2015, 1, 1-7. 
15. Sells, E.; Bailard, S.; Smith, Z.; Bowyer, A.; Olliver, V. RepRap: The Replicating Rapid PrototyperMaximizing Customizability by Breeding the Means of Production. In Proceedings of the World Conference on Mass Customization and Personalization, Cambridge, MA, USA, 7-10 October 2007.

16. Jones, R.; Haufe, P.; Sells, E.; Iravani, P.; Olliver, V.; Palmer, C.; Bowyer, A. RepRap-the replicating rapid prototyper. Robotica 2011, 29, 177-191.

17. Bowyer, A. 3D Printing and humanity's first imperfect replicator. 3D Print. Addit. Manuf. 2014, 1, 4-5.

18. Kietzmann, J.; Pitt, L.; Berthon, P. Disruptions, decisions, and destinations: Enter the age of 3-D printing and additive manufacturing. Bus. Horiz. 2015, 58, 209-215.

19. Lipson, H.; Kurman, M. Fabricated: The New World of 3D Printing; John Wiley \& Sons, 2013.

20. Gwamuri, J.; Wittbrodt, B.; Anzalone, N.; Pearce, J. Reversing the trend of large scale and centralization in manufacturing: The case of distributed manufacturing of customizable 3-d-printable self-adjustable glasses. Chall. Sustain. 2014, 2, 30-40.

21. Attaran, M. The rise of 3-D printing: The advantages of additive manufacturing over traditional manufacturing. Bus. Horiz. 2017, 60, 677-688.

22. Tanikella, N.G.; Wittbrodt, B.; Pearce, J.M. Tensile strength of commercial polymer materials for fused filament fabrication 3D printing. Addit. Manuf. 2017, 15, 40-47.

23. Baden, T.; Chagas, A.M.; Gage, G.; Marzullo, T.; Prieto-Godino, L.L.; Euler, T. Open labware: 3-D printing your own lab equipment. PLoS Biol. 2015, 13, e1002086, doi:10.1371/journal.pbio.1002086.

24. Coakley, M.; Hurt, D.E. 3D Printing in the laboratory: Maximize time and funds with customized and opensource labware. J. Lab. Autom. 2016, 21, 489-495.

25. Zhang, C.; Wijnen, B.; Pearce, J.M. Open-Source 3-D platform for low-cost scientific instrument ecosystem. J. Lab. Autom. 2016, 21, 517-525.

26. Dhankani, K.C.; Pearce, J.M. Open source laboratory sample rotator mixer and shaker. HardwareX 2017, 1, $1-12$.

27. Trivedi, D.K.; Pearce, J.M. Open Source 3-D Printed Nutating Mixer. Appl. Sci. 2017, 7, 942.

28. Zhang, C.; Anzalone, N.C.; Faria, R.P.; Pearce, J.M. Open-Source 3D-Printable Optics Equipment. PLoS ONE 2013, 8, e59840.

29. Winters, B.J.; Shepler, D. 3D printable optomechanical cage system with enclosure. HardwareX 2018, 3, 6281.

30. Agcayazi, T.; Foster, M.; Kausche, H.; Gordon, M.; Bozkurt, A. Multi-axis stress sensor characterization and testing platform. HardwareX 2019, 5, e00048.

31. Delmans, M.; Haseloff, J. $\mu$ Cube: A Framework for 3D Printable Optomechanics. 2018. https://www.repository.cam.ac.uk/handle/1810/278797

32. Sharkey, J.P.; Foo, D.C.W.; Kabla, A.; Baumberg, J.J.; Bowman, R.W. A one-piece 3D printed flexure translation stage for open-source microscopy. Review of Scientific Instruments 2016, 87, 025104.

33. Collins, J.T.; Knapper, J.; Stirling, J.; Mduda, J.; Mkindi, C.; Mayagaya, V.; Mwakajinga, G.A.; Nyakyi, P.T.; Sanga, V.L.; Carbery, D.; et al. Robotic microscopy for everyone: the OpenFlexure Microscope. bioRxiv 2019, 861856.

34. Grant, S.D.; Cairns, G.S.; Wistuba, J.; Patton, B.R. Adapting the 3D-printed Openflexure microscope enables computational super-resolution imaging. F1000Res 2019, 8, 2003.

35. Anzalone, G.C.; Glover, A.G.; Pearce, J.M. Open-Source Colorimeter. Sensors 2013, 13, 5338-5346.

36. Kelley, C.D.; Krolick, A.; Brunner, L.; Burklund, A.; Kahn, D.; Ball, W.P.; Weber-Shirk, M. An Affordable Open-Source Turbidimeter. Sensors 2014, 14, 7142-7155.

37. Wijnen, B.; Anzalone, G.C.; Pearce, J.M. Open-source mobile water quality testing platform. J. Water Sanit. Hyg. Dev. 2014, 4, 532-537.

38. Wittbrodt, B.T.; Squires, D.A.; Walbeck, J.; Campbell, E.; Campbell, W.H.; Pearce, J.M. Open-Source Photometric System for Enzymatic Nitrate Quantification. PLoS ONE 2015, 10, e0134989.

39. Wijnen, B.; Hunt, E.J.; Anzalone, G.C.; Pearce, J.M. Open-Source Syringe Pump Library. PLoS ONE 2014, 9 , e107216.

40. Bravo-Martinez, J. Open source 3D-printed $1000 \mu \mathrm{L}$ micropump. HardwareX 2018, 3, 110-116.

41. Pusch, K.; Hinton, T.J.; Feinberg, A.W. Large volume syringe pump extruder for desktop 3D printers. HardwareX 2018, 3, 49-61.

42. Garcia, V.E.; Liu, J.; DeRisi, J.L. Low-cost touchscreen driven programmable dual syringe pump for life science applications. HardwareX 2018, 4, e00027. 
43. Klar, V.; Pearce, J.M.; Kärki, P.; Kuosmanen, P. Ystruder: Open source multifunction extruder with sensing and monitoring capabilities. HardwareX 2019, 6, e00080.

44. Pearce, J.M.; Anzalone, N.C.; Heldt, C.L. Open-Source Wax RepRap 3-D Printer for Rapid Prototyping Paper-Based Microfluidics. J. Lab. Autom. 2016, 21, 510-516.

45. Lake, J.R.; Heyde, K.C.; Ruder, W.C. Low-cost feedback-controlled syringe pressure pumps for microfluidics applications. PLoS One 2017, 12.

46. Kong, D.S.; Thorsen, T.A.; Babb, J.; Wick, S.T.; Gam, J.J.; Weiss, R.; Carr, P.A. Open-source, communitydriven microfluidics with Metafluidics. Nat. Biotechnol. 2017, 35, 523-529.

47. Niezen, G.; Eslambolchilar, P.; Thimbleby, H. Open-source hardware for medical devices. BMJ Innov. 2016, $2,78-83$.

48. Daniel K., F.; Peter J., G. Open-Source Hardware Is a Low-Cost Alternative for Scientific Instrumentation and Research. Modern Instrumentation 2012, 2012.

49. Pearce, J.M. Laboratory equipment: Cut costs with open-source hardware. Nature 2014, 505, 618.

50. Pearce, J.M., Impacts of Open Source Hardware in Science and Engineering. Bridge 2017, 47, $24-31$.

51. Pearce, J. Quantifying the Value of Open Source Hardware Development. Mod. Econ. 2015, 6, 1-11.

52. Pearce, J.M. Return on investment for open source scientific hardware development. Sci. Public Policy 2016, 43, 192-195.

53. Hietanen, I.; Heikkinen, I.T.S.; Savin, H.; Pearce, J.M. Approaches to open source 3-D printable probe positioners and micromanipulators for probe stations. HardwareX 2018, 4, e00042.

54. Dryden, M.D.M.; Fobel, R.; Fobel, C.; Wheeler, A.R. Upon the Shoulders of Giants: Open-Source Hardware and Software in Analytical Chemistry. Anal. Chem. 2017, 89, 4330-4338.

55. Quartz Crystal Microbalance with Dissipation Monitoring: the first scientific QCM entirely Open Source Available online: https://openqcm.com/ (accessed on Apr 7, 2020).

56. Politi, J.; Dardano, P.; Caliò, A.; Iodice, M.; Rea, I.; De Stefano, L. Reversible sensing of heavy metal ions using lysine modified oligopeptides on porous silicon and gold. Sensors and Actuators B: Chemical 2017, 244, 142-150.

57. Frijns, E.; Verstraelen, S.; Stoehr, L.C.; Van Laer, J.; Jacobs, A.; Peters, J.; Tirez, K.; Boyles, M.S.P.; Geppert, M.; Madl, P.; et al. A Novel Exposure System Termed NAVETTA for In Vitro Laminar Flow Electrodeposition of Nanoaerosol and Evaluation of Immune Effects in Human Lung Reporter Cells. Environ. Sci. Technol. 2017, 51, 5259-5269.

58. Ventura, B.D.; Iannaccone, M.; Funari, R.; Ciamarra, M.P.; Altucci, C.; Capparelli, R.; Roperto, S.; Velotta, R. Effective antibodies immobilization and functionalized nanoparticles in a quartz-crystal microbalancebased immunosensor for the detection of parathion. PLOS ONE 2017, 12, e0171754.

59. Fries, M.D.F. The Opera Instrument: An Advanced Curation Development for Mars Sample Return Organic Contamination Monitoring.; Woodlands, TX, United States, 2018.

60. Muckley, E.S.; Naguib, M.; Ivanov, I.N. Multi-modal, ultrasensitive, wide-range humidity sensing with Ti3C2 film. Nanoscale 2018, 10, 21689-21695.

61. Scale Manufacturers Association Load Cell Application and Test Guideline. 2010. Available online: http://www.scalemanufacturers.org/pdf/loadcellapplicationtestguidelineapril2010.pdf (accessed on Apr 13, 2020).

62. Xiamen Ocular 1602 LCD Data Sheet Available online: https://www.sparkfun.com/datasheets/LCD/GDM1602K.pdf (accessed on Mar 30, 2020).

63. AVIA Semiconductor HX711 Data Sheet Available online: https://cdn.sparkfun.com/datasheets/Sensors/ForceFlex/hx711 english.pdf (accessed on Mar 30, 2020).

64. Arduino Arduino - Board Available online: https://www.arduino.cc/en/reference/board (accessed on Mar 30, 2020).

65. Scale Manufacturers Association SMA SCP-0499 Scale Serial Communication Protocol 1999 Available online: http://www.scalemanufacturers.org/PDF/ScaleCommProtocol5199M1.pdf (accessed on Apr 13, 2020).

66. Arduino Nano Available online: https://store.arduino.cc/usa/arduino-nano (accessed on Apr 6, 2020).

67. Banggood.com Geekcreit Nano V3 Module With USB Cable Available online: https:/www.banggood.com/ATmega328P-Nano-V3-Module-Improved-Version-With-USB-CableDevelopment-Board-p-933647.html (accessed on Apr 6, 2020).

68. AmazonBasics USB A-miniB Available online: https://www.amazon.com/AmazonBasics-USB-2-0-CableMale/dp/B00NH13S44 (accessed on Apr 6, 2020). 
69. Amazon 5V USB Wall Charger Available online: https://www.amazon.com/Certified-Charger-FONKENuniversal-

Compatible/dp/B07DCR29GN/ref=sr 13 3 crid=2T9NB566GJAS4\&dchild=1\&keywords=5v+usb+power+su pply\&qid $=1586183620 \& s=$ electronics\&sprefix $=5 \mathrm{v}+\mathrm{usb}+\mathrm{p} \% 2$ Celectronics $\% 2$ C213\&sr $=1-3$ (accessed on Apr 6, 2020).

70. Amazon HX711 and TAL220 Available online: https://www.amazon.com/KNACRO-Converter-BreakoutPortable-Electronic/dp/B078W2VCP2/ref=sr 1 1 ?dchild=1\&keywords=tal220\&qid=1586183945\&sr=8$1 \&$ th=1 (accessed on Apr 6, 2020).

71. Industries, Adafruit. Tactile Button switch $(6 \mathrm{~mm})$ x 20 pack Available online: https://www.adafruit.com/product/367 (accessed on Apr 6, 2020).

72. Industries, Adafruit. Adafruit Full sized breadboard Available online: https://www.adafruit.com/product/239 (accessed on Apr 6, 2020).

73. Banggood.com Banggood 40pcs Double Side Prototype PCB Available online: https://www.banggood.com/Geekcreit-40pcs-FR-4-2 54mm-Double-Side-Prototype-PCB-Printed-CircuitBoard-p-995732.html (accessed on Apr 6, 2020).

74. Arducam 1602 16x2 LCD Display Module Available online: https://www.amazon.com/Arducam-DisplayController-Character-Backlight/dp/B019D9TYMI (accessed on Apr 6, 2020).

75. Potentiometers I Mouser Available online: https://www.mouser.com/Passive-Components/PotentiometersTrimmers-Rheostats/Potentiometers//N-9q0yp?Ns=Pricingl0 (accessed on Apr 14, 2020).

76. Resistor Kit - 1/4W (500 total) - COM-10969 - SparkFun Electronics Available online: https://www.sparkfun.com/products/10969 (accessed on Apr 6, 2020).

77. Headers, Adafruit Available online: https://www.adafruit.com/category/154 (accessed on Apr 6, 2020).

78. HTC-Sensor TAL220 Sheet Available online: https://cdn.sparkfun.com/datasheets/Sensors/ForceFlex/TAL220M4M5Update.pdf (accessed on Apr 4, 2020).

79. HTC-Sensor TAL221 Data Sheet Available online: https://cdn.sparkfun.com/assets/9/9/a/f/3/TAL221.pdf (accessed on Apr 4, 2020).

80. Mini Load Cell - 100g, Straight Bar (TAL221), SparkFun Electronics Available online: https://www.sparkfun.com/products/14727 (accessed on Apr 6, 2020).

81. Open source laboratory logging digital scale https://osf.io/me9a8/ DOI 10.17605/OSF.IO/ME9A8

82. GNU General Public License Version 3. Available online: https://www.gnu.org/licenses/gpl-3.0.en.html (accessed on 29 March 2019).

83. Cura LulzBot Edition. Available online: https://www.lulzbot.com/cura (accessed on 2 April 2019).

84. LulzBot LulzBot TAZ 6 Available online: https://www.lulzbot.com/store/printers/lulzbot-taz-6 (accessed on Apr 20, 2020).

85. Fritzing Available online: http://fritzing.org/ (accessed on Mar 28, 2020).

86. Arduino HelloWorld Available online: https://www.arduino.cc/en/Tutorial/HelloWorld (accessed on Mar 28, 2020).

87. SparkFun Basic Character LCD Hookup Guide - learn.sparkfun.com Available online: https://learn.sparkfun.com/tutorials/basic-character-lcd-hookup-guide (accessed on Mar 30, 2020).

88. bogde HX711; 2020; Available online: https://github.com/bogde/HX711 (accessed on Apr 13, 2020).

89. Hans-Christoph Steiner LiquidCrystal; Arduino Libraries, 2020; Available online: https://github.com/arduino-libraries/LiquidCrystal (accessed on Apr 13, 2020).

90. Denver Instruments APX-402 Operators Manual. Available online: http://www.denverinstrument.com/denverusa/media/pdf/archive manuals/Op-Man-Apex-RevC.pdf (accessed on 16 April 2019).

91. Denver Instruments A-160 Operators Manual. Available online: http://www.denverinstrument.com/denverusa/media/pdf/archive manuals/OpMan A-Series.pdf (accessed on 16 April 2019).

92. Sule, S.S.; Petsiuk, A.L.; Pearce, J.M. Open Source Completely 3-D Printable Centrifuge. Instruments 2019, 3, 30.

93. EIA.

Electric

Power

Monthly.

Available

online: https://www.eia.gov/electricity/monthly/epm table grapher.php? $\mathrm{t}=\mathrm{epmt} 56$ a (accessed on 16 April 2019). 
94. White $\mathrm{MH}$ Build Series PLA Filament - $2.85 \mathrm{~mm} \quad(1 \mathrm{~kg})$ Available online: https://www.matterhackers.com/store/3d-printer-filament/300mm-pla-filament-white-1-kg (accessed on Apr 20, 2020).

95. eBay Denver APX 402 Scale for sale online Available online: https://www.ebay.com/c/669060320 (accessed on Apr 14, 2020).

96. eBay Denver A-160 Digital Scale for sale online Available online: https://www.ebay.com/itm/DenverInstruments-Company-Digital-Scale-A-160-/161055820362 (accessed on Apr 14, 2020).

97. Amazon.com AMIR Digital Kitchen Scale, 500g-0.01g Available online: https://www.amazon.com/AMIRUpgraded-500g-0-01g-Stainless-Batteries/dp/B01HCKQG7G (accessed on Apr 22, 2020).

98. Amazon.com: Lab Analytical Balance Scale, 500gx0.01g High Precision Electronic Scientific Scale Peeling Weight Digital Kitchen Precision Balance Jewelry Gold Scale with 200g Weight Self-Correcting Function (US): Industrial \& Scientific [WWW Document], n.d. URL https://www.amazon.com/Analytical-500gx001g-Electronic-Scientific-Self-Correcting/dp/B08591CKQT/ (accessed 4.23.20).

99. Amazon.com: Mein LAY Lab Analytical Electronic Balance Scale Laboratory Balance Digital Kitchen Balance Scale Jewelry Gold Scale Precision Balance (0.01/2000g): Home \& Kitchen [WWW Document], n.d. URL https://www.amazon.com/Mein-LAY-Analytical-Electronic-Laboratory/dp/B07VRCSFBY/ (accessed 4.23.20).

100. Amazon.com: U.S. SOLID 0.001g 1mg Analytical Digital Lab Precision Balance Scale 300g: Amazon.com: Industrial \& Scientific [WWW Document], n.d. URL https://www.amazon.com/U-S-Analytical-DigitalPrecision-Balance/dp/B017ADAA7C/ (accessed 4.23.20).

101. Amazon.com U.S. Solid 0.001g 1mg Digital Analytical Balance w/ RS232 Interface Available online: https://www.amazon.com/U-S-Solid-Analytical-Laboratories-Calibration/dp/B07Y2SXMTC (accessed on Apr 22, 2020).

102. Amazon.com U.S. Solid Precision Lab Scale $1000 \mathrm{~g}$ x 0.01g- High Precision Analytical Balance w/ RS232 Interface, Detachable Draft Shield, Calibration Weight, 100-240 VAC: Amazon.com: Industrial \& Scientific [WWW Document], n.d. URL https://www.amazon.com/U-S-Solid-Precision-AnalyticalDetachable/dp/B07YL1B146/?th=1 (accessed 4.23.20).

103. Amazon.com CGOLDENWALL 5000g 5kg 0.01g Lab Analytical Balance RS232 Available online: https://www.amazon.com/Analytical-Precision-Electronic-Calibration-Commercial/dp/B07DCM3CFC (accessed on Apr 22, 2020).

104. Ross, A. R. and Lewin, K. M., “Science Kits in developing Countries: An Appraisal of Potential," Int. Inst. Of Education and Planning UNESCO Report, 1 -120 (1992).

105. Gwamuri, J.; Pearce, J.M. Open source 3D printers: an appropriate technology for building low cost optics labs for the developing communities. In Proceedings of the 14th Conference on Education and Training in Optics and Photonics: ETOP 2017; International Society for Optics and Photonics, 2017; Vol. 10452, p. 104522S.

106. De Maria, C.; Di Pietro, L.; Ravizza, A.; Lantada, A.D.; Ahluwalia, A.D. Chapter 2 - Open-source medical devices: Healthcare solutions for low-, middle-, and high-resource settings. In Clinical Engineering Handbook (Second Edition); Iadanza, E., Ed.; Academic Press, 2020; pp. 7-14 ISBN 978-0-12-813467-2.

107. Pearce, J. Distributed Manufacturing of Open-Source Medical Hardware for Pandemics. Preprints 2020, 2020040054 (doi: 10.20944/preprints202004.0054.v1).

108. Clare Sebastian and Valentina Di Donato, CNN In the race to secure medical supplies, countries ban or restrict exports Available online: https://www.cnn.com/2020/03/27/business/medical-supplies-exportban/index.html (accessed on Apr 15, 2020).

109. Pearce, J.M. Undermined by overhead accounting. Science 2016, 352, 158-159.

110. SparkFun OpenScale Applications and Hookup Guide - SparkFun Available online: https://learn.sparkfun.com/tutorials/openscale-applications-and-hookup-guide\#calibration-suggestions (accessed on Mar 16, 2020).

111. SparkFun OpenLog - DEV-13712 Available online: https://www.sparkfun.com/products/13712 (accessed on Apr 14, 2020).

112. GMM Technoworld 50kg/1g 2kg/0.05g Digital Counting Scale with Dual Platter \& PC connection Available online: https://testmeter.sg/webshaper/store/viewprod.asp?pkproductitem $=432 \&$ pkproduct $=$ (accessed on Apr 22, 2020). 